Published in final edited form as:

Curr Rheumatol Rep. 2013 December ; 15(12): 387. doi:10.1007/s11926-013-0387-2.

\title{
Yoga in Rheumatic Diseases
}

\author{
Susan J. Bartlett, PhD \\ Divisions of Rheumatology and Clinical Epidemiology, McGill University, Montreal Canada, \\ Division of Rheumatology, Johns Hopkins University, Baltimore, MD \\ Steffany Haaz, PhD \\ Corporate Health Solutions, 2500 York Road, Jamison, Pa 18929 \\ Christopher Mill, BSc \\ Division of Clinical Epidemiology, McGill University Health Centre, Montreal, Quebec, Canada \\ Sasha Bernatsky, MD PhD \\ Division of Rheumatology and Division of Clinical Epidemiology, McGill University Health Centre, \\ Montreal, Quebec, Canada
}

Clifton O. Bingham III, MD

Division of Rheumatology, Johns Hopkins University, Baltimore, MD. 5200 Eastern Avenue, Mason F. Lord Bldg, Center Tower, Room 404, Baltimore, MD 21224

\section{Abstract}

Yoga is a popular activity which may be well suited for some individuals with certain rheumatic disorders. Regular yoga practice can increase muscle strength and endurance, proprioception and balance, with emphasis on movement through a full range of motion to increase flexibility and mobility. Additional beneficial elements of yoga include breathing, relaxation, body awareness and meditation, which can reduce stress and anxiety and promote a sense of calmness, general well-being and improved quality of life. Yoga also encourages a meditative focus, increased body awareness and mindfulness; some evidence suggests yoga may help decrease inflammatory mediators including C-reactive protein and interleukin-6. Yoga is best learned under the supervision of qualified teachers who are well informed about the potential musculoskeletal needs of each individual. Here, we briefly review the literature on yoga in healthy, musculoskeletal, and rheumatic disease populations and offer recommendations for discussing ways to begin yoga with patients.

\section{Keywords}

yoga; rheumatic diseases; arthritis; osteoarthritis; rheumatoid arthritis; system lupus erythematosus

Corresponding author: Susan J. Bartlett, PhD, Associate Professor of Medicine, Royal Victoria Hospital, Division of Clinical Epidemiology, 687 Pine Ave W. Ross, 4-31, Montreal, Canada, H3A 1A1, Phone: 514 843-1465, susan.bartlett@ mcgill.ca. shaaz@corporatehealthsolutions.com. (443) 801-0539. Christopher.mill@ mail.mcgill.ca. Sasha.Bernatsky@ mcgill.ca. (410) 550-0578 cbingha2@jhmi.edu. 


\section{Introduction}

Regular physical activity is essential for overall health and wellbeing, centers prominently in public health recommendations [1], and is included in treatment guidelines for arthritis [2;3], fibromyalgia (FM) [4;5] and other rheumatic diseases. Emerging evidence suggests that yoga, which offers a mind-body approach to physical activity and emphasizes healthy living, may be particularly well suited for some individuals with certain types of rheumatic diseases.

\section{What is Yoga?}

Yoga is an ancient Indian practice dating back several thousand years, with the goal of uniting mind, body, and spirit.[6] There are several branches of yoga, which share a common underlying philosophy and include a variety of lifestyle practices. In western cultures, Hatha yoga is most commonly practiced, and the physical movements of yoga are often emphasized as a form of exercise with both physical benefits and improvements in well-being. Hatha yoga generally includes a set of physical poses (asanas) that may be fluid or static, coordinated with breathing techniques (pranayama), as well as deep relaxation (sivasana) and/or meditation. Hatha yoga may also include some degree of chanting, mudras (hand positions), and/or discussion of yogic philosophy.

There are many styles of Hatha yoga, each with its own style and approach, that may be optimal for different populations (see Table 1). Performing the physical poses can improve fitness by increasing strength, flexibility and balance.[7;8] Yoga practice typically begins with a slow sequence of continuous movements to increase blood flow and warm muscles. This is followed by a series of diverse poses which can engage muscles in all areas of the body in flexion, extension, adduction, abduction and rotation. Many yoga poses can increase muscle strength and endurance, and standing poses can also increase proprioception and balance.[6] Many poses also emphasize movement through a full range of motion to increase flexibility and mobility.

Yoga also includes additional elements that distinguish it from traditional forms of exercise. The breathing, relaxation, and meditative elements of yoga can potentially reduce stress and anxiety, distract from negative thoughts, and promote a sense of calmness, general wellbeing and improved quality of life. Yoga encourages the use of a meditative focus, body awareness and respect of individual limits while engaging in poses. Mindfulness, or orientation to the present moment with a sense of curiosity, openness and acceptance, is also a core feature of yoga. Yoga practice also often includes discussion of core yogic principles including non-harming of self and others, appropriate energy expenditure, contentment with "what is," and ongoing self-study which may benefit persons living with rheumatic diseases.

\section{Who Practices Yoga and Why?}

Interest in yoga has increased significantly in the past two decades, and it is now widely available in many community centers, fitness clubs, yoga studios, and worksite settings. In 2012, it was estimated that 20 million US adults (or 9\% of the population) were practicing yoga, most of whom were participating with the goal of improving health and fitness.[9] 
According to the 2002 National Health Interview Survey (NHIS) Alternative Medicine Supplement, regular practitioners of yoga were mostly female (76\%), white (85\%) and well educated (50\% had college).[10] People practicing yoga were more likely than nonpractitioners to rate their health as excellent, very good or good (95\% vs. $87 \%$, respectively). Interestingly, having a musculoskeletal condition was independently associated with a higher odds of practicing yoga regularly (OR 1.61, 95\% confidence interval 1.42-1.83).

The top five reasons reported for starting yoga were to improve flexibility (78\%), general conditioning (62\%), stress (60\%), overall health (59\%) and physical fitness (55\%).[9] Indeed, there is considerable evidence that people who practice yoga rate their health more positively. A 2013 national survey of 1087 individuals who regularly practiced yoga reported improvements in energy (85\%), happiness (86\%), social relationships (67\%), sleep (69\%) and weight (57\%).[11] Among German patients seen in an integrative internal medicine clinic, $12 \%$ reporting using yoga to address their chronic pain; the three most common diagnoses were spinal pain (19\%), headache (12\%) and FM (12\%).[12]

The potential for yoga to enhance health and wellbeing appears to have been embraced by the medical community as well. A 2008 market study commissioned by Yoga Journal using a nationally representative sample of US adults suggested that $6.1 \%$, or nearly 14 million Americans, reported that a doctor or therapist recommended yoga to them, and nearly half (45\%) stated they believed yoga would be beneficial.[13]

\section{Health Benefits of Yoga}

There appears to be general agreement of the potential health benefits associated with yoga. On their website, the National Center for Complementary and Alternative Medicine (NCCAM) of the National Institutes of Health (NIH) states that yoga is a safe and effective in healthy people when practiced appropriately under the guidance of a well-trained instructor, and lists several health conditions including low-back pain, for which yoga may be beneficial.[14] In the UK, the National Health Service (NHS) promotes yoga as a safe and effective method to increase physical activity in both healthy persons and those with a range of health conditions.[15]

Physical fitness and health-Overall, the reported health and fitness benefits of yoga are similar to those associated with other forms of exercise, especially in older populations. [7;16-20] A 2011 systematic review of yoga studies in older adults concluded that yoga was associated with moderate improvements in gait, balance, flexibility, lower body strength, and weight loss.[21] However, the impact of yoga on cardiovascular conditioning is less clear. Some forms of yoga practice may not be of sufficient intensity to improve or maintain cardiovascular fitness. For example, in one study, metabolic expenditure was measured during a 30 minute session of beginner level yoga using a room calorimeter. The investigators concluded that when averaged across the entire session, total metabolic expenditure reflected an overall low level of physical activity that was equivalent to walking $1.5 \mathrm{mph}$ on a treadmill.[22] The large variability in yoga styles and doses, as well the range of outcomes assessed, make comparisons of yoga with other forms of exercise and across 
studies challenging to interpret. Clearly, more research is needed to establish the conditioning effects of yoga on health.

Musculoskeletal system-Unfortunately, there is limited scientific evidence available on how yoga specifically impacts the musculoskeletal system. Wang et al. recently studied the biomechanical impact of yoga on the lower extremity associated with the static phase of 7 common standing yoga poses in seniors.[23] Not surprisingly, physical demands on the ankle, knee and hip in the frontal and sagittal planes varied significantly across the different poses. However, as this is one of the first studies to develop biomechanical profiles of yoga poses, the investigators noted that additional work is needed to better characterize other commonly used poses, as well as the effects of modifications, and between-pose transitions. Understanding the biomechanical profiles of yoga poses is a first step to designing evidencebased programs that can target specific joints and muscle groups to prevent or address impairments in function and mobility.

Psychological and immune function-Nearly four decades of research has shown that people who practice yoga generally report improvements in mood (i.e., anxiety, depression) and ability to deal with stress, as well as greater feelings of emotional and social wellbeing. [17;24-26] There is growing evidence that yoga is associated with down-regulation of the hypothalamic-pituitary adrenal (HPA) axis as well as the sympathetic nervous system.[17] There is some suggestion that yoga may help decrease levels of inflammatory markers including C-reactive protein and interleukin-6.[27;28]

\section{Health Benefits in Clinical Populations}

In response to the growing number of studies reported in the medical literature, several systematic reviews and meta-analyses have been recently published evaluating the health benefits of yoga in clinical populations. McCall et al. recently completed a Cochrane overview of systematic reviews of yoga in adults with 13 chronic health conditions.[29] The strongest evidence of the potential benefit of yoga is for improving pain (standardized mean difference $[\mathrm{SMD}]-.74 ; 95 \%$ confidence interval $[\mathrm{CI}]-.97$ to -.52 ), with similar effects evident for reductions in pain-related disability (SMD -.79 (95\% CI -1.02 to -.56$)$ and improvements in mood (SMD -.65; 95\% CI - .89 to -.42).[8] There is also evidence that when added to standard treatments, yoga can improve outcomes associated with several mental health conditions including depression, anxiety (including post-traumatic stress disorder), and schizophrenia (SMD -3.25; 95\% CI -5.36, -1.14).[30] However, not all health conditions may benefit from yoga. For example, meta analyses have not supported evidence of improvement in asthma [24] or with menopausal symptoms[31].

There are significant challenges in conducting systematic reviews of yoga studies. For example, in the 2012 meta-analysis of yoga and pain, while higher quality studies reported better pain outcomes, important limitations were also noted.[8] The best effects were seen in the shortest studies. Longer trials were associated with challenges associated with most exercise interventions including suboptimal adherence. Studies were conducted in different countries and settings, using non-randomized designs and relatively small samples that were often poorly characterized. There was significant heterogeneity in the populations studied, 
comparison groups and outcomes assessed. Most interventions were poorly described and varied widely in duration, frequency and intensity.

\section{Yoga in People with Rheumatic Conditions}

There are several reasons to believe why the combination of physical and mental components of yoga may be well suited to people living with arthritis and other rheumatic diseases. For example, relaxation, imagery and biofeedback, as adjuncts to conventional therapy, can improve pain and mood, as well as physical functioning and coping, particularly in the early stages of rheumatoid arthritis (RA).[32] Mindfulness has been shown to decrease stress, as well as improve mood in RA [33] and FM.[34] Other aspects of yoga may be particularly important for individuals with musculoskeletal concerns including the emphasis on acknowledging and accepting day to day variability in feelings of wellbeing and energy, enhancing body awareness and respecting limits, and modifying exercise (mode, duration, frequency) in response to transient changes in disease activity.

The physical exercise associated with yoga also may build strength in the lower extremities. Three common poses (Crescent, Warrior II and One-legged Balance) target three functionally important motor groups simultaneously - namely, hip flexors and extensors, knee flexors and extensors and ankle plantar flexors.[23] Notably, strengthening of these motor groups can prevent collapse of the center of mass during standing and walking.[23]

In 2011, we conducted a scoping review of 7 studies evaluating yoga in arthritis (5 in RA and 2 in both osteoarthritis (OA) and RA).[35] There was significant heterogeneity in study design, populations studied, and interventions tested. For example, while many studies included validated instruments and used blinded assessors, arthritis disease activity was assessed using a range of indicators. Outcomes ranged from changes in symptoms, function, and mobility to improvements in fitness parameters including strength, balance, and flexibility. The type of yoga varied considerably across settings as did dose. Funding for the studies ranged from federal or foundational grants to support in one case from a large department store. We concluded that overall the studies were of very low to low quality, and the heterogeneity of the studies precluded meta-analysis. Nevertheless, there was a consistent trend suggesting some evidence of improvement in pain, function, mood, energy, and self-efficacy with regular yoga practice. None of the studies reported evidence of disease worsening or increased joint symptoms, and there was some very preliminary evidence of improvement in disease activity including reductions in tender and swollen joint counts. More recently, Cramer et al. conducted a systematic review of RCTs that evaluated yoga as an adjunctive intervention in FM (2 studies), OA (3 studies), RA (2 studies) and carpal tunnel syndrome (CTS; 1 study).[36] They also concluded that although quality of evidence was very low to low quality (and hence strength of recommendation), as an ancillary intervention, yoga was associated with improvements in pain and disability in FM, OA and RA. (Though the original reports of the CTS study found no evidence for the effects of yoga on CTS, reanalysis as part of a Cochrane review indicated some evidence of benefit associated with yoga.[37]) Ward et al. also completed a meta-analysis of 16 studies of yoga on selected musculoskeletal conditions (low back pain [11], RA[1], OA[2], FM[1], kyphosis[1]) judged to be of good quality. They also reported moderate treatment effects for 
yoga on pain (SMD of $-.61 ; 95 \%$ CI -.97 to -.26 ) and functional outcomes (SMD of -.64; $95 \%$ CI -.89 to -.39$)$.[38]

We have recently completed pragmatic randomized trials of yoga in arthritis and lupus that were not included in these reviews. At the Johns Hopkins Arthritis Center in Baltimore (SJB, SH, COB), Maryland, 75 adults with OA or RA (half with RA) were randomized to 8weeks of yoga or a control group receiving usual care. In brief, two 60-min classes were combined with one home practice/week. Classes consisted of gentle yoga poses including forward bends, backbends, twists, and balance poses which were completed while standing, sitting or lying down. Modifications were provided to individuals to address affected joints, as needed, and participants were encouraged to try new skills but avoid joint discomfort. Standard props including blocks, straps, blankets and chairs were encouraged as needed based on individual limitations. Outcomes assessed included physical hhealth perceptions, along with selected indicators of physical fitness, psychological functioning and disease activity (for those with RA). At the end of 8 weeks, as compared with usual care, individuals who participated in the yoga arm reported significantly higher ratings of physical health, mood and physical function and showed improvements in flexibility and balance. Among participants with RA, there was a trend for swollen and tender joint counts and patient global assessment scores to improve in both groups at the end of treatment. No related adverse events were reported.

We (CM, SB) also recently implemented a similar protocol for people with systemic lupus erythematosus (SLE) seen at the McGill University Health Centers Lupus Clinic in Montreal, Canada. A total of 57 patients were randomly assigned to yoga or usual care. The 8 week yoga intervention provided 60-minute classes twice weekly that included gentle poses along with home practice. Focus groups and surveys of yoga participants conducted one week after completion of the interventions indicated participants perceived an improvement in overall well-being, improved stress and pain management, healthier relationships, and better sleep. Participants expressed satisfaction with the program content and teacher. Most participants stated that they first began to notice benefits well into the program and would have preferred if duration had been longer than 8 weeks. All participants wished to continue yoga but were hesitant to try programs not designed for SLE.

Our studies offer further preliminary evidence that yoga appears to be a safe, feasible, and adaptable to the needs of individuals with arthritis and lupus. Interestingly, several participants in both the arthritis and lupus studies stated that they felt yoga had helped them learn more about themselves, their bodies and to be more accepting of and positive about the prospect of living with a rheumatic disease.

\section{Talking with Patients about Yoga}

Medical considerations-Yoga is one component of a regular exercise program that can help improve strength, balance, and flexibility. There are, of course, general medical considerations that should be reviewed prior to undertaking any exercise program, including yoga (see Table 2). Patients with rheumatic diseases also may have unique needs so discussion with the treating rheumatologist and/orthopedist is necessary to identify vulnerable joints as well as poses or motions that should be avoided or modified. 
What style of yoga?-The optimal way for all to start may be with a gentle yoga approach with emphasis on proceeding slowly and gradually. Some forms of yoga are generally appropriate for most people with rheumatic diseases at any age, while a few are not recommended for individuals with movement limitations and chronic pain (see Table 1). For example, Bikram or "hot yoga" may not be suitable both from a cardiac perspective as well as the increased potential for overstretching. More strenuous forms of yoga such as Ashtanga (sometimes called power yoga), particularly in older individuals who are not used to exercise, should only be undertaken if there are no concerns regarding cardiovascular issues, neurological deficits, etc. In the setting of joint replacement, consultation with the treating orthopedic team should be made. Vinyasa yoga keeps participants moving throughout the class, sometimes quickly. Even with props/ modifications, the continuous movement during vinyasa yoga can is often challenging for deconditioned individuals, or anytime fatigue significantly increases and thus is not recommended in many instances. On the other hand, restorative yoga, which focuses on being completely supported by props with minimal physical exertion is particularly appropriate on days when individuals feel fatigued or may be having a flare.

Additional considerations-For certain patients, it may be advisable to avoid specific poses that are common across many yoga styles. Persons with serious painful joint involvement or damage, and particularly previous joint replacement, must be cautious and avoid yoga positions that involve movements that may be contraindicated. For example, the American Academy of Orthopedic Surgeons recommends that people who have undergone hip replacement avoid bringing the knees up higher than the hip, leaning forward while sitting, standing with toes pointed together, bending at the waist beyond 90 degree, and kneeling.[39] Thus, after hip replacement, it is important to modify yoga poses that call for significant external rotation (e.g., cobbler), or extension of the leg backward (e.g., Warrior II).

Because seniors typically have lesser joint flexibility, strength and balance and a greater prevalence of osteoarthritis and back-pain syndromes (e.g. spinal-canal stenosis, disc disease), they are at greater risk of developing musculoskeletal and neurological complications (e.g. strains, sprains, \& impingements) when participating in yoga [23]. However, the needs of seniors can be adequately managed through modifications for standard poses and the use of props (e.g., seated yoga) to reduce the risk of injury (see Table 3). For these reasons, yoga is best learned under the supervision of qualified teachers who are well informed about and can adapt practice to the individual musculoskeletal needs.

\section{Helping Patients Find Qualified Yoga Instruction}

Many people living with rheumatic diseases express interest in yoga, but also question whether classes offered in community settings are safe and appropriate for their needs. Although there are several DVDs available that have been designed for people with arthritis, it is always prudent to begin with live instruction to ensure proper form and safety before practicing without supervision.[14] 
Currently, there are no credentialing requirements for teaching yoga in most states.

However, there are two organizations that promote standards in training and continuing education. The Yoga Alliance registers yoga teachers (RYT) after completion of a comprehensive 200-hour program with a registered yoga training school. The Yoga Alliance requires a minimum number of contact hours in teaching methodology, anatomy and physiology, yoga philosophy, and practicum. Yoga teachers can go on to pursue a 500-hour certification, and can also earn a designation of E-RYT-200 or E-RYT-500 which signifies additional teaching experience.

In recent years, the field of yoga therapy has emerged and distinguished itself from general yoga teaching. While yoga instructors typically teach classes to healthy populations, yoga therapists typically offer smaller groups or private sessions to individuals with conditions such as arthritis or other movement limitations. Yoga therapists are also employed by many large academic centers (e.g., UCLA, Memorial Sloan Kettering, Mayo Clinic, Boston University Medical Center). The Cleveland Clinic currently employs a full-time yoga therapist to oversee yoga classes and programming throughout the institution. The International Association of Yoga Therapists has recommended core competencies for 800 hours of training that will be required of yoga therapy training programs (beyond the initial 200 hours required for registration as a yoga teacher.) This 1000-hour of basic training is expected to be followed by additional continuing education and may include specialization with a specific population. However, it is important to note that the title "therapist" is not protected and essentially anyone can call themselves a yoga therapist, or pay a small fee to be "certified" as a therapist. In addition, since oversight of yoga therapy training is still emerging, it is especially important that anyone with a rheumatic disease ask directly about the training, experience, and specialization of potential instructors.

It is important to recognize that there is the potential for injury with any style of yoga (and any type of exercise), especially during periods when disease activity may be increased (e.g., flares), or when exercising strenuously or for long periods of time. All patients should be advised to immediately stop engaging in any pose that brings on pain. Classes should include periods of rest, and "resting poses" are always appropriate and important to include as part of regular yoga practice. Instructors should be equipped to assist the student in modifying the practice to meet their individual needs, or should recommend a class such as gentle yoga that may be more appropriate. Individuals with greater restrictions may first want to begin working privately with a yoga therapist to learn modifications that they can utilize in classes or during home practice.

\section{Conclusion}

Yoga has become an increasingly popular option for physical activity that can offer important health and quality of life benefits. Painful musculoskeletal conditions (and pain in general) are two primary reasons that many people pursue yoga. Taken together, the growing body of evidence from studies suggests yoga is a reasonably safe and feasible option for many people living with rheumatic conditions. This holistic approach to exercise with an emphasis on mindfulness and stress reduction may also offer additional 
opportunities to enhance psychological well-being, reduce pain and enhance function and participation, as part of a comprehensive disease management approach.

Before engaging in yoga, individuals should first discuss this with their health care provider. Initial practice should include direct supervision by a qualified instructor, who is knowledgeable about potential joint and musculoskeletal limitations and can suggest the use of props and modifications as needed to ensure safety and comfort. However, once individuals are comfortable with the practice, yoga can be core aspect of a healthy, positive and active lifestyle.

\section{Reference List}

1. US Department of Health and Human Services 2008 physical activity guidelines for Americans. Accessed on: 9-20-2013. Available at: http://www.health.gov/PAGuidelines

2. Hochberg MC, Altman RD, April KT, Benkhalti M, Guyatt G, McGowan J, Towheed T, Welch V, Wells G, Tugwell P. American College of Rheumatology 2012 recommendations for the use of nonpharmacologic and pharmacologic therapies in osteoarthritis of the hand, hip, and knee. Arthritis Care Res (Hoboken.). 2012; 64:465-474. [PubMed: 22563589]

3. American College of Rheumatology Subcommittee on Rheumatoid Arthritis Guidelines. Guidelines for the management of rheumatoid arthritis: 2002 Update. Arthritis Rheum. 2002; 46:328-346. [PubMed: 11840435]

4. Carville SF, Arendt-Nielsen S, Bliddal H, Blotman F, Branco JC, Buskila D, Da Silva JA, Danneskiold-Samsoe B, Dincer F, Henriksson C, Henriksson KG, Kosek E, Longley K, McCarthy GM, Perrot S, Puszczewicz M, Sarzi-Puttini P, Silman A, Spath M, Choy EH. EULAR evidencebased recommendations for the management of fibromyalgia syndrome. Ann Rheum Dis. 2008; 67:536-541. [PubMed: 17644548]

5. Fitzcharles MA, Ste-Marie PA, Goldenberg DL, Pereira JX, Abbey S, Choiniere M, Ko G, Moulin DE, Panopalis P, Proulx J, Shir Y. Canadian Pain Society and Canadian Rheumatology Association Recommendations for Rational Care of Persons with Fibromyalgia. A Summary Report. J.Rheumatol. 2013; 40:1388-1393. [PubMed: 23818709]

6. McCall, T. Yoga as Medicine. Bantam Dell; New York, NY: 2007.

7. Raub JA. Psychophysiologic effects of Hatha Yoga on musculoskeletal and cardiopulmonary function: a literature review. J Altern.Complement Med. 2002; 8:797-812. [PubMed: 12614533]

8. Bussing A, Ostermann T, Ludtke R, Michalsen A. Effects of yoga interventions on pain and painassociated disability: a meta-analysis. J Pain. 2012; 13:1-9. [PubMed: 22178433]

9. Yoga Journal. Yoga in America - 2012. Yoga Journal; San Francisco, CA: 2012.

10. Birdee GS, Legedza AT, Saper RB, Bertisch SM, Eisenberg DM, Phillips RS. Characteristics of yoga users: results of a national survey. J Gen.Intern Med. 2008; 23:1653-1658. [PubMed: 18651193]

11. Ross A, Friedmann E, Bevans M, Thomas S. National survey of yoga practitioners: Mental and physical health benefits. Complement Ther.Med. 2013; 21:313-323. [PubMed: 23876562]

12. Cramer H, Lauche R, Langhorst J, Paul A, Michalsen A, Dobos G. Predictors of yoga use among internal medicine patients. BMC Complement Altern.Med. 2013; 13:172. [PubMed: 23849549]

13. Yoga in America - 2008. Yoga Journal; San Francisco, CA: 2008.

14. National Center for Complementary and Alternative Medicine National Institutes of Health. Yoga for Health: What the Science Says. Accessed on: 8-14-2012. Available at: http://nccam.nih.gov/ health/providers/digest/yoga-science

15. NHS NHS. Your health, your choices: A guide to yoga. Accessed on: 8-23-2013. Available at: http://www.nhs.uk/Livewell/fitness/Pages/yoga.aspx

16. Harle P, Pongratz G, Weidler C, Buttner R, Scholmerich J, Straub RH. Possible role of leptin in hypoandrogenicity in patients with systemic lupus erythematosus and rheumatoid arthritis. Ann Rheum Dis. 2004; 63:809-816. [PubMed: 15194576] 
17. Ross A, Thomas S. The health benefits of yoga and exercise: a review of comparison studies. $\mathrm{J}$ Altern.Complement Med. 2010; 16:3-12. [PubMed: 20105062]

18. Patel NK, Newstead AH, Ferrer RL. The effects of yoga on physical functioning and health related quality of life in older adults: a systematic review and meta-analysis. J.Altern.Complement Med. 2012; 18:902-917. [PubMed: 22909385]

19. Tiedemann A, O'Rourke S, Sesto R, Sherrington C. A 12-Week Iyengar Yoga Program Improved Balance and Mobility in Older Community-Dwelling People: A Pilot Randomized Controlled Trial. The Journals of Gerontology Series A: Biological Sciences and Medical Sciences. 2013; 68:1068-1075.

20. Oken BS, Zajdel D, Kishiyama S, Flegal K, Dehen C, Haas M, Kraemer DF, Lawrence J, Leyva J. Randomized, controlled, six-month trial of yoga in healthy seniors: effects on cognition and quality of life. Altern.Ther.Health Med. 2006; 12:40-47. [PubMed: 16454146]

21. Roland KP, Jakobi JM, Jones GR. Does yoga engender fitness in older adults? A critical review. J Aging Phys.Act. 2011; 19:62-79. [PubMed: 21285476]

22. Hagins M, Moore W, Rundle A. Does practicing hatha yoga satisfy recommendations for intensity of physical activity which improves and maintains health and cardiovascular fitness? BMC Complementary and Alternative Medicine. 2007; 7:40. [PubMed: 18053143]

23. Wang MY, Yu SSY, Hashish R, Samarawickrame S, Kazadi L, Greendale G, Salem G. The biomechanical demands of standing yoga poses in seniors: The Yoga empowers seniors study (YESS). BMC Complementary and Alternative Medicine. 2013; 13:8. [PubMed: 23302513]

24. Kirkwood G, Rampes H, Tuffrey V, Richardson J, Pilkington K. Yoga for anxiety: a systematic review of the research evidence. Br.J Sports Med. 2005; 39:884-891. [PubMed: 16306493]

25. Cramer H, Lauche R, Langhorst J, Dobos G. Yoga for depression: A systematic review and metaanalysis. Depress.Anxiety. 2013

26. da Silva TL, Ravindran LN, Ravindran AV. Yoga in the treatment of mood and anxiety disorders: A review. Asian Journal of Psychiatry. 2009; 2:6-16. [PubMed: 23051013]

27. Pullen PR, Nagamia SH, Mehta PK, Thompson WR, Benardot D, Hammoud R, Parrott JM, Sola S, Khan BV. Effects of Yoga on Inflammation and Exercise Capacity in Patients With Chronic Heart Failure. J.Card.Fail. 2008; 14:407-413. [PubMed: 18514933]

28. Kiecolt-Glaser JK, Christian L, Preston H, Houts CR, Malarkey WB, Emery CF, Glaser R. Stress, Inflammation, and Yoga Practice. Psychosomatic Medicine. 2010; 72:113-121. [PubMed: 20064902]

29. McCall MC, Ward A, Roberts NW, Heneghan C. Overview of systematic reviews: yoga as a therapeutic intervention for adults with acute and chronic health conditions.

Evid.Based.Complement Alternat.Med. 2013; 2013:945895. [PubMed: 23762174]

30. Cabral P, Meyer HB, Ames D. Effectiveness of yoga therapy as a complementary treatment for major psychiatric disorders: a meta-analysis. Prim Care Companion.CNS.Disord. 2011; 13

31. Lee MS, Kim JI, Ha JY, Boddy K, Ernst E. Yoga for menopausal symptoms: a systematic review. Menopause. 2009; 16:602-608. [PubMed: 19169169]

32. Astin JA, Beckner W, Soeken K, Hochberg MC, Berman B. Psychological interventions for rheumatoid arthritis: A meta-analysis of randomized controlled trials. Arthritis Care Res. 2002; 47:291-302.

33. Pradhan EK, Baumgarten M, Langenberg P, Handwerger B, Gilpin AK, Magyari T, Hochberg MC, Berman BM. Effect of Mindfulness-Based stress reduction in rheumatoid arthritis patients. Arthritis Care Res. 2007; 57:1134-1142.

34. Sephton SE, Salmon P, Weissbecker I, Ulmer C, Floyd A, Hoover K, Studts JL. Mindfulness meditation alleviates depressive symptoms in women with fibromyalgia: Results of a randomized clinical trial. Arthritis Care Res. 2007; 57:77-85.

35. Haaz S, Bartlett SJ. Yoga for arthritis: a scoping review. Rheum Dis Clin North Am. 2011; 37:3346. [PubMed: 21220084]

36. Cramer H, Lauche R, Langhorst J, Dobos G. Yoga for rheumatic diseases: a systematic review. Rheumatology.(Oxford). 2013

37. Page MJ, O'Connor D, Pitt V, Massy-Westropp N. Exercise and mobilisation interventions for carpal tunnel syndrome. Cochrane Database Syst Rev. 2012; 6:CD009899. [PubMed: 22696387] 
38. Ward L, Stebbings S, Cherkin D, Baxter GD. Yoga for Functional Ability, Pain and Psychosocial Outcomes in Musculoskeletal Conditions: A Systematic Review and Meta-Analysis. Musculoskelet.Care. 2013

39. American Academy of Orthopaedic Surgeons Activities After Hip Replacement. Accessed on: 10-7-2013. Available at: http://orthoinfo.aaos.org/topic.cfm?topic=A00356 


\section{Table 1}

Common yoga styles, characteristics and appropriateness for individuals with rheumatic diseases. *

\begin{tabular}{|c|c|c|}
\hline Style & Characteristics & Recommendations \\
\hline Ananda & $\begin{array}{l}\text { Very gentle preparation for meditation. } \\
\text { Affirmations combined with poses. }\end{array}$ & $\begin{array}{l}\text { Longer meditation in static positions may be } \\
\text { difficult for some. }\end{array}$ \\
\hline Anusara & $\begin{array}{l}\text { Anatomically-based. Extensive teacher } \\
\text { training. }\end{array}$ & $\begin{array}{l}\text { Recommended for most people with rheumatic } \\
\text { conditions. }\end{array}$ \\
\hline Ashtanga & $\begin{array}{l}\text { Specific sequence. Continuous } \\
\text { movement. Very strenuous. } \\
\text { (Sometimes called power yoga.) }\end{array}$ & Not recommended due to physical rigor. \\
\hline Bikram/Hot & $\begin{array}{l}\text { Taught in } 100-110 \text { degree room to } \\
\text { expel toxins and increase mobility. }\end{array}$ & $\begin{array}{l}\text { Not recommended due to extreme heat. } \\
\text { Cardiovascular clearance should be obtained } \\
\text { prior to undertaking. }\end{array}$ \\
\hline Chair & $\begin{array}{l}\text { All poses practiced while sitting in a } \\
\text { chair. }\end{array}$ & $\begin{array}{l}\text { Recommended for deconditioned seniors and } \\
\text { anyone with balance or mobility limitations. }\end{array}$ \\
\hline Gentle & $\begin{array}{l}\text { Optimal for people with lower fitness } \\
\text { levels. Emphasizes a slower and more } \\
\text { careful practice. }\end{array}$ & $\begin{array}{l}\text { Recommended for most people with rheumatic } \\
\text { conditions. }\end{array}$ \\
\hline Integral & $\begin{array}{l}\text { Gentle practice including poses, } \\
\text { breathing, chants, and meditation. }\end{array}$ & $\begin{array}{l}\text { Recommended for most people with rheumatic } \\
\text { conditions. }\end{array}$ \\
\hline Iyengar & $\begin{array}{l}\text { Strong anatomical basis. Uses props } \\
\text { to individualize poses. }\end{array}$ & $\begin{array}{l}\text { Recommended for most people with rheumatic } \\
\text { conditions. }\end{array}$ \\
\hline Kripalu & $\begin{array}{l}\text { Taught in three stages with evolving } \\
\text { emphasis. Stage One focuses on } \\
\text { learning poses and understanding the } \\
\text { body. }\end{array}$ & $\begin{array}{l}\text { First stage recommended for most people with } \\
\text { rheumatic conditions. }\end{array}$ \\
\hline Kundalini & $\begin{array}{l}\text { Intended to awaken latent spiritual } \\
\text { energy through poses, breathing, and } \\
\text { meditation. }\end{array}$ & $\begin{array}{l}\text { Intensity of breathing techniques, long sitting, and } \\
\text { expansive arm movements may be challenging } \\
\text { for some individuals. }\end{array}$ \\
\hline Pre-natal & $\begin{array}{l}\text { Classes intended for expectant } \\
\text { mothers, with a focus on mindfulness, } \\
\text { breath, and safety. }\end{array}$ & $\begin{array}{l}\text { While not intended for people with rheumatic } \\
\text { diseases, classes progress slowly with emphasis } \\
\text { on individual attention; can offer an alternative to } \\
\text { more rigorous classes. }\end{array}$ \\
\hline Restorative & $\begin{array}{l}\text { "Resting" poses which are fully } \\
\text { supported with props to allow muscle } \\
\text { release and relaxation. }\end{array}$ & $\begin{array}{l}\text { Recommended for most people with rheumatic } \\
\text { conditions but does not build strength, balance or } \\
\text { flexibility. May be especially appropriate during } \\
\text { flares or periods of fatigue. }\end{array}$ \\
\hline Sivananda & $\begin{array}{l}\text { Gentle practice including poses, } \\
\text { breathing, chants, and meditation. }\end{array}$ & $\begin{array}{l}\text { Recommended for people with rheumatic } \\
\text { conditions. }\end{array}$ \\
\hline $\begin{array}{l}\text { Vinyasa } \\
\text { (Flow) }\end{array}$ & $\begin{array}{l}\text { Individualized practice. Extensive } \\
\text { coordination between breath and } \\
\text { movement. Extensive teacher training. }\end{array}$ & $\begin{array}{l}\text { Continuous movement during vinyasa yoga is } \\
\text { often challenging and may move too quickly to } \\
\text { allow for modifications and use of props. } \\
\text { Beginner/gentle vinyasa recommended with } \\
\text { reservations for some inddividuals. }\end{array}$ \\
\hline Yin & $\begin{array}{l}\text { Often used to prepare for extended } \\
\text { meditation in static poses. Poses are } \\
\text { held in the full position to encourage } \\
\text { release. Promotes flexibility but not } \\
\text { strength or balance. }\end{array}$ & $\begin{array}{l}\text { May be suitable for some; however, there is a } \\
\text { potential for overstretching and tendon } \\
\text { inflammation. }\end{array}$ \\
\hline
\end{tabular}

* Note: Within styles there may be significant variability in terms of emphasis and difficulty. Before participation, a discussion with the class instructor may be helpful to understand the specifics for the class. 
Table 2

Recommendations for health care providers to consider for rheumatic disease patients prior to participating in yoga.

- Primum non nocere: Importance of principle of "non-harming" in medicine and yoga

- Evaluate general health and overall endurance

- Evaluate co-morbid cardiovascular and pulmonary disease (may require referral to other specialists)

- Assess for severe osteoporosis (risk of fracture/fall)

- Clearly identify vulnerable joints to the patient (e.g., joints with instability, at particular risk for injury, with limited mobility, active swelling or underlying damage, and any joints that have been replaced.) In all of these cases, the patient should be aware of the need for caution and to avoid positions that include movements contra-indicated after a hip or other joint replacement. Patients should be advised to listen to their body throughout class, avoiding movements that bring on pain. Patients should always review possible problem areas and limitations with the instructor prior to starting the class.

- Review warning signs of injury and appropriate management of discomfort (e.g. rest, cold, heat)

- Consider providing a letter for yoga instructor outlining general and specific medical and musculoskeletal concerns. Care providers can also agree to speak directly with the yoga instructor and provide a contact number.

- Engage in ongoing dialog with patient concerning their yoga experience and concerns

- Consider physical and/or occupational therapist assessment of limitations/modifications 
Table 3

Potential modifications and props that can be used to adapt yoga poses to specific musculoskeletal needs.

\begin{tabular}{|llll|}
\hline Joint & Limitation & Pose & Potential Modification \\
\hline Knee & Extreme flexion & Tree & Keep the foot at the opposite ankle \\
\hline & Patellar weight bearing & $\begin{array}{l}\text { Table (support on } \\
\text { hands and knees) }\end{array}$ & Place blanket under knees \\
\hline Hip & $\begin{array}{l}\text { External rotation to } \\
\text { edge of ROM }\end{array}$ & $\begin{array}{l}\text { Easy Pose (sitting } \\
\text { crossed leg) }\end{array}$ & Blocks under knees \\
\hline & Flexion beyond $90^{\circ}$ & Extended leg & Strap around foot to reduce angle \\
\hline Wrist & $\begin{array}{l}\text { Extension with weight } \\
\text { bearing }\end{array}$ & Downward Dog & Place wedge under palms \\
\hline Hand & Flattened palms & Prayer Position & Rest hands on heart \\
\hline Shoulder & $\begin{array}{l}\text { Arms above shoulder } \\
\text { height }\end{array}$ & Chair Pose & Arms extended forward \\
\hline Ankle & $\begin{array}{l}\text { Flexion with weight } \\
\text { bearing }\end{array}$ & Warrior I & Wedge under heel \\
\hline Foot & Forced arch & Low Lunge & Rest top of the foot on the floor \\
\hline Spine & $\begin{array}{l}\text { Lumbar Flexion } \\
\text { Lumbar Extension } \\
\text { Cervical Extension }\end{array}$ & $\begin{array}{l}\text { Forward fold } \\
\text { Bridge } \\
\text { Upward dog }\end{array}$ & $\begin{array}{l}\text { Keep deep bend in knees } \\
\text { Support block under small of back } \\
\text { Keep neck neutral }\end{array}$ \\
\hline
\end{tabular}

* Table reflects only a small representation of the types of modifications and use of props. 